\title{
INTERNATIONAL BULLETIN OF BACTERIOLOGICAL NOMENCLATURE AND TAXONOMY
}

Volume 5 No. 4 October 15, 1955 pp. $151-152$

TWO NEW SALMONELLA TYPES:

S. SEATTLE AND S. PORTLAND

P.R. Edwards and Alma C. McWhorter

Communicable Disease Center, Public Health Service, U.S. Department of Health, Education, and Welfare Atlanta, Georgia

Salmonella portland (culture 4484-54) was isolated in the laboratories of the Oregon State Department of Health and forwarded to the writers by Dr. William Levin as a group D Salmonella serotype with a request for specific identification. The organism was found in abdominal fluid obtained from a 60-year-old female patient by paracentesis. Two weeks prior to hospital admission the patient had been affected with chills, fever, anorexia, chest pains, and jaundice. After treatment with various antibiotics the temperature subsided to $102^{\circ} \mathrm{F}$. Nothing was learned concerning the subsequent course of the illness.

S. portland produced hydrogen sulfide, failed to form indol, to hydrolyze urea, or to liquefy gelatin, was methyl red positive and Voges-Proskauer negative. The organism grew readily on Simmons 'citrate agar but failed to grow on Moeller's KCN medium. The organism was motile, reduced nitrates, and acidified Jordan's tartrate agar. Glucose, xylose, arabinose, rhamnose, trehalose, mannitol, and sorbitol were fermented promptly with the production of gas. Unlike

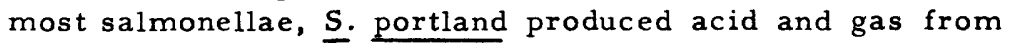
raffinose after 24 hours incubation. Lactose, sucrose, salicin, inositol, dulcitol, and adonitol were not fermented.

The culture was agglutinated to the titre of Salmonella gallinarum $O$ serum $(9,12)$ and in absorption tests removed all agglutinins from the serum. The $\mathrm{H}$ antigens were diphasic. Phase 1 was agglutinated to the titre of Salmonella illinois, phase $l\left(z_{10}\right)$ serum. In absorption tests $\underline{\underline{S}}$. portland reduced the titre of the serum from 10,000 to 500 and left a residue of agglutinins for phase 1 of Salmonella eschweiler $\left(6,7: z_{10}-1,6\right)$, Salmonella tel hashomer $\left(11: z_{10}-\overline{c, n, x), \text { and }}\right.$ an unnamed Salmonella type having the formula $11: z_{10}-1,2$.

Phase 2 of $\underline{S}$. portland was agglutinated by serums derived from all the nonspecific phases of the genus. In tests with single factor serums, agglutination occurred in absorbed 
serum for factor 5 but not in serums for factors 2,6 , or 7 , The organism reacted to the titre of serum for phase 2 of Salmonella thompson $(1,5)$ and in absorption tests reduced the titre of the serum from 20,000 to 1,000. All agglutinins for phase 2 of Salmonella panama $(9,12: 1, v-1,5)$ were removed from the serum. The antigenic formula of $\underline{S}$. portland is $9,12: z_{10}-1,5$.

Salmonella seattle (culture 2775-54) was isolated in the laboratories of Seattle-King County Department of Health from the feces of a 6 weeks old child affected with severe diarrhea and was forwarded for identification by Miss $M$. Mulhern. The organism was found repeatedly in the stools of the infant. The child, as well as two siblings and the mother, developed gastrointestinal symptoms in Khartoum before leaving for the United States. No pathogenic forms were recognized in the stools of the siblings but Shigella flexneri 4 was isolated from the mother.

The biochemical properties of $\mathrm{S}$. seattle were the same as those of $\underline{S}$. portland except that the former fermented dulcitol promptly and failed to ferment raffinose. Upon serological examination it was found that $S$. seattle was agglutinated to the titre of antiserum of Salmonella $\mathrm{O}$ antigen 28. This serum, which was prepared from a monophasic Salmonella culture having the antigenic formula $28: y$, retained a pronounced residue of agglutinins for the homologous strain after absorption with $\underline{S}$. seattle. However, there was a complete removal of agglutinins for three unnamed Salmonella types possessing $O$ antigen 28 .

The $\mathrm{H}$ antigens of $\mathrm{S}$. seattle were diphasic and phase 1 agglutinated to the titre of, and removed all $\mathrm{H}$ agglutinins from, serum derived from Salmonella paratyphi $A(a)$. Phase 2 was agglutinated actively by serums derived from antigens $e, n, x$ and $e, n, z_{15}$. It reacted with absorbed serum for factor $x$ but not with serum for factor $z_{15}$. In absorption tests the organism removed all $\mathrm{H}$ agglutinins from serum derived from Salmonella abortus-equi $(e, n, x)$. The antigenic formula

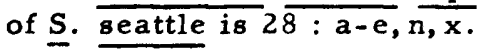

\section{SUMMARY}

Two new Salmonella serotypes isolated from infections in man are described. $S$. portland represented by the antigenic formula $9,12: z_{10^{-1}}, \overline{5}$; s. seattle by the formula $28: a-e, n, x$. 